\title{
Interpretation of Actinide-Distribution Data Obtained from Non-Destructive and Destructive Post-Test Analyses of an Intact-Core Column of Culebra Dolomite
}

\author{
W. George Perkins \\ WIPP Regulatory Compliance Department \\ Sandia National Laboratories \\ Albuquerque, NM 87185-1395 \\ Daniel A. Lucero \\ WIPP Chemical and Disposal Room Processes Department \\ Sandia National Laboratories \\ Albuquerque, NM 87185-1320
}

\begin{abstract}
The U.S. DOE, with technical assistance from Sandia National Laboratories, has successfully received EPA certification and opened the Waste Isolation Pilot Plant (WIPP), a nuclear waste disposal facility located approximately $42 \mathrm{~km}$ east of Carlsbad, New Mexico. Performance assessment analyses indicate that human intrusions by inadvertent, intermittent drilling for resources provide the only credible mechanisms for releases of radionuclides from the disposal system. In modeling long-term brine releases, subsequent to a drilling event, potential migration pathways through the permeable layers of rock above the Salado formation were analyzed. Major emphasis is placed on the Culebra Member of the Rustler Formation because this is the most transmissive geologic layer overlying the WIPP site. In order to help quantify parameters for the calculated releases, radionuclide transport experiments have been carried out using intact-core columns obtained from the Culebra dolomite member of the Rustler Formation within the WIPP site. This paper deals primarily with results of analyses for ${ }^{241} \mathrm{Pu}$ and ${ }^{241} \mathrm{Am}$ distributions developed during transport experiments in one of these cores. Transport experiments were done using a synthetic brine that simulates Culebra brine at the core recovery location (the WIPP air-intake shaft - AIS). Hydraulic characteristics (i.e., apparent porosity and apparent dispersion coefficient) for intact-core columns were obtained via experiments using the conservative tracer ${ }^{22} \mathrm{Na}$. Elution experiments carried out over periods of a few days with tracers ${ }^{232} \mathrm{U}$ and ${ }^{239} \mathrm{~Np}$ indicated that these tracers were weakly retarded as indicated by delayed elution of the species. Elution experiments with tracers ${ }^{241} \mathrm{Pu}$ and ${ }^{241} \mathrm{Am}$ were attempted, but no elution of either species has been observed to date, including experiments of many months' duration. In order to quantify retardation of the non-eluted species ${ }^{241} \mathrm{Pu}$ and ${ }^{241} \mathrm{Am}$ after a period of brine flow, nondestructive and destructive analyses of one intact-core column were carried out to determine distribution of these actinides in the rock. Analytical results indicate that the majority of the ${ }^{241} \mathrm{Am}$ remained very near the injection surface of the core (possibly as a precipitate), and that the majority of the ${ }^{241} \mathrm{Pu}$ was dispersed with a very high apparent retardation value. The ${ }^{241} \mathrm{Pu}$ distribution is interpreted using a single-porosity advection-dispersion model, and an approximate retardation value is reported.
\end{abstract}




\section{DISCLAIMER}

This report was prepared as an account of work sponsored by an agency of the United States Government. Neither the United States Government nor any agency thereof, nor any of their employees, make any warranty, express or implied, or assumes any legal liability or responsibility for the accuracy, completeness, or usefulness of any information, apparatus, product, or process disclosed, or represents that its use would not infringe privately owned rights. Reference herein to any specific commercial product, process, or service by trade name, trademark, manufacturer, or otherwise does not necessarily constitute or imply its endorsement, recommendation, or favoring by the United States Government or any agency thereof. The views and opinions of authors expressed herein do not necessarily state or reflect those of the United States Government or any agency thereof. 


\section{DISCLAIMER}

Portions of this document may be illegible in electronic image products. Images are produced from the best available original document. 


\section{INTRODUCTION}

The U.S. Department of Energy (DOE), with technical assistance from Sandia National Laboratories, has successfully received EPA certification and opened the Waste Isolation Pilot Plant (WIPP), which is designed for the safe disposal of transuranic waste produced by the defense nuclear-weapons program. The U.S. Environmental Protection Agency (U.S. EPA, 1993) sets limits on cumulative radioactive releases to the accessible environment over a 10,000 year period and requires that Performance Assessment (PA) analyses be performed to demonstrate WIPP compliance with its regulation. These analyses (U.S. DOE, 1996) indicate that the only credible mechanisms for significant releases of radionuclides from the disposal system result from human intrusion by inadvertent and intermittent drilling for resources. Releases are modeled to occur by five mechanisms: (1) cuttings, (2) cavings, (3) spallings, (4) direct brine releases, and (5) long-term brine releases through a degraded borehole. The first four mechanisms could result in immediate release of contaminant to the accessible environment. For the last mechanism, major emphasis is placed on migration through the Culebra Member of the Rustler Formation, the most transmissive geologic layer overlying the Salado halites, which are the host formation for the WIPP repository.

Empirical batch sorption experiments have provided most of the actinide-dolomite sorption values submitted for performance assessment calculations (Brush, 1996). Flow experiments with intact-core columns of Culebra dolomite have also been used to demonstrate actinide retardation. The intact-core column flow experiments have provided information on the effects of advective fluid flow on sorption behavior in the Culebra dolomite at small scale (Lucero et al., 1998). In these experiments, steady state brine flows were first established in several intact-core columns that had been recovered from the Culebra at the location of the WIPP Air-Intake Shaft (AIS). Although various brine compositions could be important. (e.g., brines from the Castile formation which underlies the Salado Formation), the experiments were conducted using brines with composition similar to that found in the Culebra at the AIS. At various times after steady-state flow was established in a given core, relatively small pulses of brine containing one or more dissolved radioactive species were injected into the general flow at the upstream end of the column. The effluent brine was then analyzed as a function of time by either $\gamma$-ray spectroscopy or liquid scintillation counting for each of the injected species.

Experimental results indicate that ${ }^{22} \mathrm{Na}^{+}$is a "conservative tracer." Elution times for ${ }^{22} \mathrm{Na}^{+}$were used to estimate core hydraulic characteristics such as apparent porosity and apparent dispersion coefficient. Actinide species ${ }^{232} \mathrm{UO}_{2}{ }^{++}$and ${ }^{239} \mathrm{NpO}_{2}{ }^{+}$have been observed to elute with some degree of retardation from all columns into which they were introduced. On the other hand, none of the isotopes ${ }^{241} \mathrm{Am},{ }^{241} \mathrm{Pu}$, and

${ }^{228} \mathrm{Th}$ have been observed to elute from any of the columns into which they were introduced. The purpose of the analyses reported here is to characterize the transport of ${ }^{241} \mathrm{Am}$ and ${ }^{241} \mathrm{Pu}$ in one of the cores. Transport retardation characteristics of the eluted radioactive species were inferred (Lucero et al., 1998) from elution time dependence using computer code COLUMN 1.4 (Budge, 1996; Brown et al., 1997). 
However, for the non-eluted actinides, transport modeling could, at best, be used to estimate minimum retardation factors (Lucero et al., 1998; Perkins et al., 1998). In order to ascertain the distribution of noneluted species, we performed non-destructive and destructive analyses of one of the cores into which noneluting actinides had been introduced.

\section{EXPERIMENTAL SUMMARY}

Intact-core column E, VPX27-7 (E-Core), was selected for post-test analysis. E-Core was obtained from the north side of WIPP air-intake shaft (AIS) at $219.8 \mathrm{~m}$ below surface. It was $10.2 \mathrm{~cm}$ long by $14.5 \mathrm{~cm}$ diameter. The estimated dry bulk density is $2.38 \mathrm{~g} / \mathrm{cm}^{3}$, and the porosity estimated from hydraulic experiments is 0.21 . In flow tests performed on E-Core, ${ }^{22} \mathrm{Na},{ }^{232} \mathrm{U},{ }^{239} \mathrm{~Np},{ }^{241} \mathrm{Pu}$, and ${ }^{241} \mathrm{Am}$ were injected into the core at various times. Radionuclides ${ }^{22} \mathrm{Na},{ }^{232} \mathrm{U},{ }^{239} \mathrm{~Np}$ did, in fact, elute, and their transport characteristics were analyzed by Lucero et al. (1998).

Brine was injected into a $6.35 \mathrm{~cm}$ diameter by $0.43 \mathrm{~cm}$ deep brine-injection well machined into one end face of the core. Brine flow was begun on December 20,1995 and maintained at $0.1 \mathrm{~mL} / \mathrm{min}$ until April 9 , 1996, when it was paused. Flow was started again on June 4, 1996 and maintained at $0.05 \mathrm{~mL} / \mathrm{min}$ until termination on July $15,1996 .{ }^{241} \mathrm{Am}(12.2 \mu \mathrm{Ci})$ and ${ }^{241} \mathrm{Pu}(11.3 \mu \mathrm{Ci})$ were injected on January 16, 1996. A second injection of ${ }^{241} \mathrm{Am}(13.4 \mu \mathrm{Ci})$ was done on March 22, 1996. The time from first injection of ${ }^{241} \mathrm{Pu}$ and ${ }^{241} \mathrm{Am}$ to the second injection of ${ }^{241} \mathrm{Am}$ was 65 days, and the time from second injection of ${ }^{241} \mathrm{Am}$ to the pause in flow was 18 days. The time from restart to end of flow was 41 days (Lucero et al., 1998).

After E-Core was removed from its aluminum pressure vessel, $\mathrm{x}$-ray films were placed on the radionuclideinjection surface for time periods up to 96 hours. The film-darkening pattern indicated the approximate distribution of ${ }^{241} \mathrm{Am}$ in and around the top-surface brine-injection well, which suggested that at least some of the ${ }^{241} \mathrm{Am}$ might have migrated outside the brine injection well. However, it was impossible to estimate migration quantitatively based on the radiographic analyses. The method used had poor resolution, on the order of several centimeters. The qualitative data were not further analyzed because of their poor spatial resolution.

Surface $\gamma$-ray counting was used to map the top-surface and longitudinal distributions of the $\gamma$-emitting

${ }^{241} \mathrm{Am}$. The $\gamma$-ray counts at various locations on the injection surface of the core were measured by moving the core on an X-Y motion table. For the longitudinal measurement, the Ge $\gamma$-ray detector was scanned vertically at 5-mm intervals from a point $5 \mathrm{~mm}$ above the top core surface to about $3 \mathrm{~cm}$ below the top surface at angular locations $0^{\circ}, 90^{\circ}, 180^{\circ}$, and $270^{\circ}$ around the core circumference. Results showed no evidence of ${ }^{241} \mathrm{Am}$ penetration beyond a depth of about $1 \mathrm{~cm}$. However, the spatial resolution for $\gamma$-ray counting was limited by the nonadjustable detector collimator aperture (5-mm diameter), and it was not possible to determine quantitatively how much ${ }^{241} \mathrm{Am}$ might actually reside outside the well boundary or to determine the longitudinal distribution to better than 1-cm resolution. As was shown by destructive analysis, the actual ${ }^{241} \mathrm{Am}$ distribution is much narrower than was obtained by low-resolution scanning. 
During destructive analysis, thin layers of rock were removed sequentially from the brine injection region of E-Core and analyzed by liquid scintillation counting (LSC). Initial destructive analysis was planned for the top centimeter just below the fluid injection well with which E-Core is equipped.

Sampling was done in a glove box using a Delta 12 -inch bench drill press with a 0.25 -inch diameter end mill. The core was secured in a Dayton 8-inch cross vise (for horizontal positioning) bolted to the drillpress table. A depth stop provided approximate vertical axis control (accurate depth of cut was inferred from recovered rock mass). The shank of the mill bit projected through a 0.375 "-diameter hole in 6 " $\mathrm{x} 6$ " $\mathrm{x}$ 0.25 " pane of Pyrex glass, positioned near the core top surface to minimize loss of powder. A vacuum hose with an in-line Nuclepore filter was positioned at the hole perimeter to capture rock powder on tare-weighed filter papers during the milling process.

Sample recovery and radiolytic analyses were performed in several steps:

- solution-injection distribution plates were acid washed to recover any sorbed actinide;

- the core was milled at $450 \mathrm{rpm}$ until a preset depth stop was reached;

- core material from a given cut was collected on the in-line filter via the vacuum hose;

- the net rock-powder mass was determined by subtracting the filter tare mass;

- the rock powder was dissolved in 75 to $150 \mathrm{~mL}$ of $0.1 \mathrm{~N} \mathrm{HCl}$;

- the acid solution was extracted by syringe and injected into several tens of test tubes;

- the activity in each test tube was determined by $\operatorname{LSC}$ for ${ }^{241} \mathrm{Am}(\alpha)$ and ${ }^{241} \mathrm{Pu}(\beta)$;

- total activity in a given cut was calculated by summing individual test-tube activities.

Total rock mass and activity were used to determine the bulk concentration of actinide in each rock layer removed.

The brine-injection well was initially $6.35 \mathrm{~cm}$ diameter and $0.43 \mathrm{~cm}$ deep (Lucero et al., 1998). The first two milling cuts were performed beginning at the floor of this well. A horizontal circumferential cut was then made (at the new well depth) to determine whether there had been significant lateral actinide migration into the wall of the well. Six additional vertical cuts were then made to increase the well depth at the new diameter, $7.2 \mathrm{~cm}$. Finally, a circumferential cut was made that added $0.8 \mathrm{~cm}$ to the well diameter to a depth of approximately $0.5 \mathrm{~cm}$. The total mass of recovered rock was recorded at the end of each cut. The depth of each cut was calculated from the recovered rock mass, the estimated rock density, and the well diameter. Total rock mass collected in each cut is recorded in the second column of Table 1. The seventh and ninth columns of Table 1 report the total ${ }^{241} \mathrm{Am}$ and ${ }^{241} \mathrm{Pu}$ activities recovered from the injection distribution plates and from each milling cut. Note that $6 \%$ to $7 \%$ of the injected quantities of both ${ }^{241} \mathrm{Pu}$ and ${ }^{241} \mathrm{Am}$ were recovered from the solution distribution plate. Each of the first few cuts was shallower than the planned $2 \mathrm{~mm}$, as evidenced by the total rock mass collected in each cut. Approximately $73 \%$ of each of the injected ${ }^{241} \mathrm{Pu}$ and the injected ${ }^{241} \mathrm{Am}$ were recovered from the distribution plate and in the top few millimeters of the core, including annular cuts. Only a miniscule quantity of either actinide was recovered in 
cuts after the fourth vertical cut, even though the majority of the rock was milled in the fifth through eighth cuts.

\section{INTERPRETATION OF EXPERIMENTAL RESULTS}

To estimate transport parameters such as retardation factor $\mathrm{R}$ and distribution coefficient $\mathrm{K}_{\mathrm{d}}$, we determined actinide concentration profiles as functions of depth and then compared these profiles with results of singleporosity transport modeling. The conceptual model thus assumed single-porosity flow and transport and a linear adsorption isotherm. Although this assumption is at best approximate for flow and transport of strongly retarded species in Culebra dolomite, it has been used as an approximation for analysis of column transport data for conservative and weakly retarded radionuclides. All numerical or mathematical analyses were performed in accordance with a formal analysis plan (Perkins, 1998) that was consistent with Sandia National Laboratories Quality Assurance Program.

Initial milling was done on the floor of the solution-injection well (diameter $\mathrm{d}_{w}=6.35 \mathrm{~cm}$; initial depth $\mathrm{h}_{w}=$ $0.43 \mathrm{~cm}$ ) at the upstream end of the core. The core dry bulk density was estimated at $\rho_{b}=2.38 \mathrm{~g} / \mathrm{cm}^{3}$ by Lucero et al. (1998). Given the recovered rock mass, $m$, and the dry bulk density $\rho_{b}$, the approximate depth of cut, $z=m /\left[\pi \rho_{b}\left(d_{w} / 2\right)^{2}\right]$. The average bulk actinide activity per unit volume in a given depth cut is estimated simply by dividing $\mathrm{A}_{A n}$ by the recovered rock volume $\mathrm{V}$. For a series of depth cuts at a given diameter, the cumulative depth for $\mathbf{n}$ cuts was calculated simply by adding the individual depths, $Z_{t o t}(n)=\Sigma$ $\mathrm{Z}_{i}(i=1, n)$. For purposes of plotting, the abscissa was taken as the average depth in each cut, $Z_{a v}(n)=$ $\left[Z_{t o t}(n)-Z_{t o t}(n-1)\right] / 2$, where $Z_{a v}(0) \equiv 0$.

Later cuts in the destructive analysis extended into the walls of the original solution-injection well, thus increasing the well diameter. The first wall cut removed $14.9 \mathrm{~g}\left(6.3 \mathrm{~cm}^{3}\right)$ of rock in an annulus around the original well. Using the initial well diameter and depth, as well as the cumulative depth of the first two cuts $(0.245 \mathrm{~cm})$ and assuming the well remained circular, the new well diameter was calculated as $7.22 \mathrm{~cm}$, which was used for calculation of cut depths after the first two.

Table 1 summarizes the results of this analysis, the ${ }^{241} \mathrm{Am}$ activity per unit rock volume is plotted in Figure 1 , and the ${ }^{241} \mathrm{Pu}$ activity per unit rock volume is plotted in Figure 2.

Estimating retardation parameters was complicated by the fact that the brine flow rate was maintained at different constant values during different segments of the experiment. However, the single-porosity model is linear and experimental observations indicated very little migration of either ${ }^{241} \mathrm{Pu}$ or ${ }^{241} \mathrm{Am}$. It seems reasonable to use eluted brine volume, rather than time, as the independent variable for comparing experimental results to model predictions. Parker and van Genuchten (1984) defined a transformation of the one-dimensional, single-porosity transport equation to dimensionless variables. This transformation permits use of eluted pore volumes rather than time as the independent variable for the transport model used. We used this variable transformation to bridge the inactive period and account for the change in flow 
rate. The transformed code output then provided dissolved actinide concentration as a function of fractional distance $(Z=z / L$, where $L=10.2 \mathrm{~cm}$ is the length of the column) through the intact-core column. Finally, calculation of actinide concentration in the rock as a function of depth requires transformation of the concentration variable from dissolved actinide concentration, $\mathrm{C}_{\mathrm{sol}}$, to concentration in the rock, $\mathrm{C}_{\mathrm{T}}$ via the formula $C_{T}=\theta C_{\text {sol }} R$, where $\theta$ is the bulk porosity, $C_{\text {sol }}$ is the dissolved concentration, and $R$ is the apparent retardation factor (Perkins and Lucero, 1998).

Using these variable transformations, we attempted to estimate retardation factors, $R$, for the actinides by comparing the observed depth profiles with profiles calculated for different values of $R$. Figure 3 compares the observed ${ }^{241} \mathrm{Am}$ profile with a profile calculated for $\mathrm{R}=10^{6}$. Note that even for such a large retardation parameter value, the observed profile is more sharply peaked than the calculated profile. Figure 4 compares the observed ${ }^{241} \mathrm{Pu}$ profile with profiles calculated for $\mathrm{R}=10^{6}$ and $\mathrm{R}=1.6 \times 10^{5}$. It is clear from Figures 3 and 4 that effective retardation values greater that $1 \times 10^{5}$ are consistent with the observed experimental data for both ${ }^{241} \mathrm{Am}$ and ${ }^{241} \mathrm{Pu}$.

\section{DISCUSSION AND CONCLUSION}

We have attempted to use a one-dimensional, single-porosity flow and transport code to obtain estimates of retardation and distribution parameters consistent with the curves displayed in Figures 1 and 2 . However, even for the very high retardation constants, the calculated depth of penetration of the actinides exceeds the observed depth of penetration. In the case of ${ }^{241} \mathrm{Am}$, it is probable that the injected actinide precipitated near the entry surface of the core. At the time of ${ }^{241} \mathrm{Pu}$ and ${ }^{241} \mathrm{Am}$ injection into E-Core (early 1996), solubility models for these species in Culebra brine were still under development. Later, Craft and Siegel (1997) calculated solubility values for $\mathrm{Am}^{3+}$ and other actinide species in an air-intake-shaft brine simulant. Calculated solubility values indicate that the first ${ }^{241} \mathrm{Am}$ spike was supersaturated by a factor of about 83 . Similarly, the second ${ }^{241} \mathrm{Am}$ spike was supersaturated by a factor of about 84 . For both spikes, it is likely that the majority of the ${ }^{241} \mathrm{Am}$ precipitated at or near the core top surface, consistent with the observed profile, which is strongly peaked near the injection surface.

The injected ${ }^{241} \mathrm{Pu}$ oxidation state was not well defined. $\mathrm{A}^{241} \mathrm{Pu}$ solution in $1 \mathrm{M} \mathrm{HCl}$ was submitted to the Los Alamos National Laboratory Chemical Science and Technology Division for oxidation-state determination in December 1994. From the discussion in the Los Alamos response, it could be argued that ${ }^{241} \mathrm{Pu}$ might have been present as either $\mathrm{Pu}^{4+}$ or $\mathrm{Pu}^{5+}$ or even as a mixture of these oxidation states. One might expect the solubility of $\mathrm{Pu}^{5+}$ to be similar to that for $\mathrm{Np}^{5+}$, as reported by Craft and Siegel (1997) as $7.84 \times 10^{-6} \mathrm{M}\left(\mathrm{pmH}=7.72\right.$, without dolomite equilibrium) and $1.1 \times 10^{-5} \mathrm{M}(\mathrm{pmH}=7.64$, with dolomite equilibrium). Similarly, one might expect the solubility of $\mathrm{Pu}^{4+}$ to be similar to that for $\mathrm{Th}^{4+}$, reported by Craft and Siegel (1997) as $1.9 \times 10^{-7} \mathrm{M}\left(\mathrm{pmH}=7.73\right.$, without dolomite equilibrium) and $1.57 \times 10^{-7} \mathrm{M}$ ( $\mathrm{pmH}=7.64$, with dolomite equilibrium). The input ${ }^{241} \mathrm{Pu}$ spike activity corresponds to a molar concentration $2.5 \times 10^{-8} \mathrm{M}$, which appears not to be saturated with respect to either $4+$ or $5+$ solubility. 
Given that the ${ }^{241} \mathrm{Pu}$ should have been soluble under the intact-core column experimental conditions, one would, perhaps, expect better agreement between calculated and observed concentration profiles in Figure 4. However, even for a dissolved species, it is worth noting that the model assumptions (single-porosity, linear adsorption isotherm, and one-dimensional transport) may not be appropriate for very high retardation values.

Using results of single-porosity modeling uncritically, we could argue from the data and computational plots of Figure 3 that ${ }^{241} \mathrm{Am}$ either exhibits a very high retardation $\left(\sim 10^{6}\right)$ or (more likely) is precipitated. Similarly, we could argue from the Figure 4 that, for ${ }^{241} \mathrm{Pu}, 1.6 \times 10^{5}<\mathrm{R}<1 \times 10^{6}$. It is reasonable to conclude that the destructive analysis results support retardation values, $\mathrm{R}>1 \times 10^{5}$, for both species ${ }^{241} \mathrm{Am}$ and ${ }^{241} \mathrm{Pu}$. For the linear isotherm approximation (Fetter, 1993), $K_{d}=(R-1) \theta / \rho_{b}$, where $\rho_{b}$ is the rock bulk density (about $2.4 \mathrm{~g} / \mathrm{cm}^{3}$ for the Culebra dolomite), $K_{d}$ is the distribution coefficient between dissolved and sorbed actinide $\left(\mathrm{cm}^{3} / \mathrm{g}\right)$, and $\theta$ is the rock porosity $(0.21$ - see Lucero et al., 1998). Inserting the parameter values given here yields $K_{d}=\left(10^{5}-1\right)(0.21) /(2.4)=8,750$.

Sensitivity analyses performed for the WIPP (Blaine, 1997) have indicated that, even for extreme scenarios, $\mathrm{K}_{\mathrm{d}}$ values greater than 3 are adequate to prevent violation of the EPA standards for release of radionuclides to the accessible environment. Clearly, then, $\mathrm{K}_{\mathrm{d}}$ values on the order of $10^{3}$ or $10^{4}$ are more than adequate to prevent violation of the EPA standards.

\section{REFERENCES}

Blaine, R. L., 1997. "Expedited CCA Activity - Evaluation of Minimum Kd Parameter Values for Culebra Transport," WPO \#41944, Sandia National Laboratories, Albuquerque, NM, January 24, 1997.

Brown, G. O., H.-T. Hsieh, and Y.-W. Lin, 1997. "COLUMN: A Computer Program for Fitting Model Parameters to Column Flow Breakthrough Curves, Version 1.4 for Windows 95/NT3.51/NT4.0," WPO \#46281, Sandia National Laboratories, Albuquerque, NM, June 13, 1997.

Brush, L. H., 1996. "Ranges and Probability Distributions of $\mathrm{K}_{\mathrm{d}} \mathrm{s}$ for Dissolved $\mathrm{Pu}, \mathrm{Am}, \mathrm{U}, \mathrm{Th}$, and $\mathrm{Np}$ in the Culebra for the PA Calculations to Support the WIPP CCA," Memorandum to M. S. Tierney, dated June 10, 1996. Albuquerque, NM: Sandia National Laboratories. (Reprinted in Appendix D of Lucero et al., 1998, pp. D-11 through D-108).

Budge, K. G., 1996. "COLUMN: A Computer Program for Fitting Model Parameters to Column Flow Breakthrough Curves, Version 1.3," WPO \#37867, Sandia National Laboratories, Albuquerque, NM.

Craft, C. C., and M. D. Siegel, 1997. "Additional Calculations of Solubility-Limited Concentrations of Actinides for Injection Spikes used in the WIPP Core Column Experiments at Sandia National Laboratories," Memorandum to D. Lucero, dated June 9, 1997. Sandia National Laboratories, Albuquerque, NM (Reprinted in Appendix D of Lucero et al., 1998, pp. D-109 through D-115).

Fetter, C. W., 1993. Contaminant Hydrogeology, pp. 117-119, Upper Saddle River, NJ: Prentice Hall. Lucero, D. A., G. O. Brown, and C. E. Heath, 1998. "Laboratory Column Experiments for Radionuclide Adsorption Studies of the Culebra Dolomite Member of the Rustler Formation," SAND97-1763, Sandia National Laboratories, Albuquerque, NM.

Parker, J. C., and M. Th. Van Genuchten, 1984. "Determining Transport Parameters from Laboratory and Field Tracer Experiments," Virginia Agricultural Experimental Station, Bulletin 84-3, Virginia Polytechnic 
Institute and State University, Blacksburg, VA. (Available from Sandia WIPP Central Files - WPO \#44584, Sandia National Laboratories, Albuquerque, NM).

Perkins, W. G., 1998. "Numerical Analysis of Data Obtained from Destructive Analysis of Culebra IntactCore Columns," SNL Analysis Plan AP-043, Rev. 00, Sandia National Laboratories, Albuquerque, NM, Effective 3/17/98. (Available from Sandia WIPP Central Files - WPO \#50463, Sandia National Laboratories, Albuquerque, NM).

Perkins, W. G., and D. A. Lucero, 1998. "Interpretation of Data Obtained from Non-Destructive and Destructive Post-Test Analyses of an Intact-Core Column of Culebra Dolomite," SAND98-0878, Sandia National Laboratories, Albuquerque, NM.

Perkins, W. G., D. A. Lucero, and G. O. Brown, 1998. "Column Experiments for Radionuclide Adsorption Studies of the Culebra Dolomite: Retardation Parameter Estimation for Non-Eluted Actinide Species," SAND98-1005, Sandia National Laboratories, Albuquerque, NM.

U.S. DOE (Department of Energy), 1996. "Title 40 CFR Part 191 Compliance Certification Application for the Waste Isolation Pilot Plant," DOE/CAO-1996-2184, Waste Isolation Pilot Plant, Carlsbad Area Office, Carlsbad, NM, October 1996.

U.S. EPA (Environmental Protection Agency), 1993. "40 CFR Part 191 Environmental Radiation Protection Standards for the Management and Disposal of Spent Nuclear Fuel, High-Level and Transuranic Radioactive Wastes; Final Rule," Federal Register. Vol. 58, no. 242, 66,398-66,416.

Sandia is a multiprogram laboratory operated by Sandia Corporation, a Lockheed Martin Company, for the United States Department of Energy under contract DE-AC04-94AL8500 
Table 1. Results of E-Core Destructive Analysis

\begin{tabular}{|c|c|c|c|c|c|c|c|c|c|c|c|}
\hline $\begin{array}{l}\text { Cut } \\
\text { Number }\end{array}$ & $\begin{array}{c}\text { Rock } \\
\text { Mass } \\
\text { (g) }\end{array}$ & \begin{tabular}{|c|} 
Rock \\
Volume \\
$\left(\mathrm{cm}^{3}\right)$
\end{tabular} & $\begin{array}{l}\text { Depth } \\
\text { of Cut } \\
\text { (cm) }\end{array}$ & $\begin{array}{c}\text { Cum. } \\
\text { Depth } \\
\text { of Cut } \\
\text { (cm) }\end{array}$ & $\begin{array}{c}\text { Plot } \\
\text { Depth } z \\
\text { (cm) }\end{array}$ & $\begin{array}{c}\text { Total } \\
\text { Am } \\
(\mathbf{n C i})\end{array}$ & $\begin{array}{c}\text { Bulk Am } \\
\text { Conc. } \\
\left(\mathrm{nCi}^{2} / \mathrm{cm}^{3}\right)\end{array}$ & $\begin{array}{c}\text { Total } \\
\text { Pu } \\
(\mathrm{nCi})\end{array}$ & $\begin{array}{c}\text { Bulk Pu } \\
\text { Conc. } \\
\left(\mathrm{nCi}^{2} / \mathbf{c m}^{3}\right)\end{array}$ & $\begin{array}{l}\mathrm{Am} \\
(\%)\end{array}$ & $\begin{array}{c}\mathrm{Pu} \\
(\%)\end{array}$ \\
\hline $\begin{array}{l}\text { Dist. } \\
\text { Plate }\end{array}$ & 0.0 & & & & & 1,800 & & 700 & & 7.0 & 6.2 \\
\hline 1 & 5.53 & 2.32 & 0.073 & 0.073 & 0.037 & 15,400 & 6,630 & 4,500 & 1950 & 60.2 & 39.8 \\
\hline 2 & 12.96 & 5.45 & 0.172 & 0.245 & 0.159 & 600 & 117 & 2,200 & 400 & 2.5 & 19.5 \\
\hline Wall \#1 & 14.92 & & & & & 800 & & 700 & & 2.9 & 6.2 \\
\hline 3 & 20.68 & 8.69 & 0.212 & 0.458 & 0.351 & 100 & 13 & 100 & 10 & 0.4 & 0.9 \\
\hline 4 & 14.39 & 6.05 & 0.148 & 0.605 & 0.531 & 80 & 13 & 100 & 17 & 0.3 & 0.9 \\
\hline 5 & 14.39 & 6.05 & 0.148 & 0.753 & 0.679 & 5 & 0.8 & 0.5 & 0.08 & 0.0 & 0.0 \\
\hline 6 & 14.18 & 5.96 & 0.146 & 0.898 & 0.826 & 3 & 0.5 & 0.2 & 0.04 & 0.0 & 0.0 \\
\hline 7 & 36.98 & 15.54 & 0.380 & 1.278 & 1.088 & 3. & 0.2 & 0.6 & 0.04 & 0.0 & 0.0 \\
\hline 8 & 40.70 & 17.10 & 0.418 & 1.696 & 1.487 & 3 & 0.2 & 0.7 & |0.04 & 0.0 & 0.0 \\
\hline Wall \#2 & 28.41 & & & & & 10 & & 2 & & 0.0 & 0.0 \\
\hline Totals & 203.14 & & & & & 18,800 & & 8,300 & & 73.4 & 73.5 \\
\hline
\end{tabular}




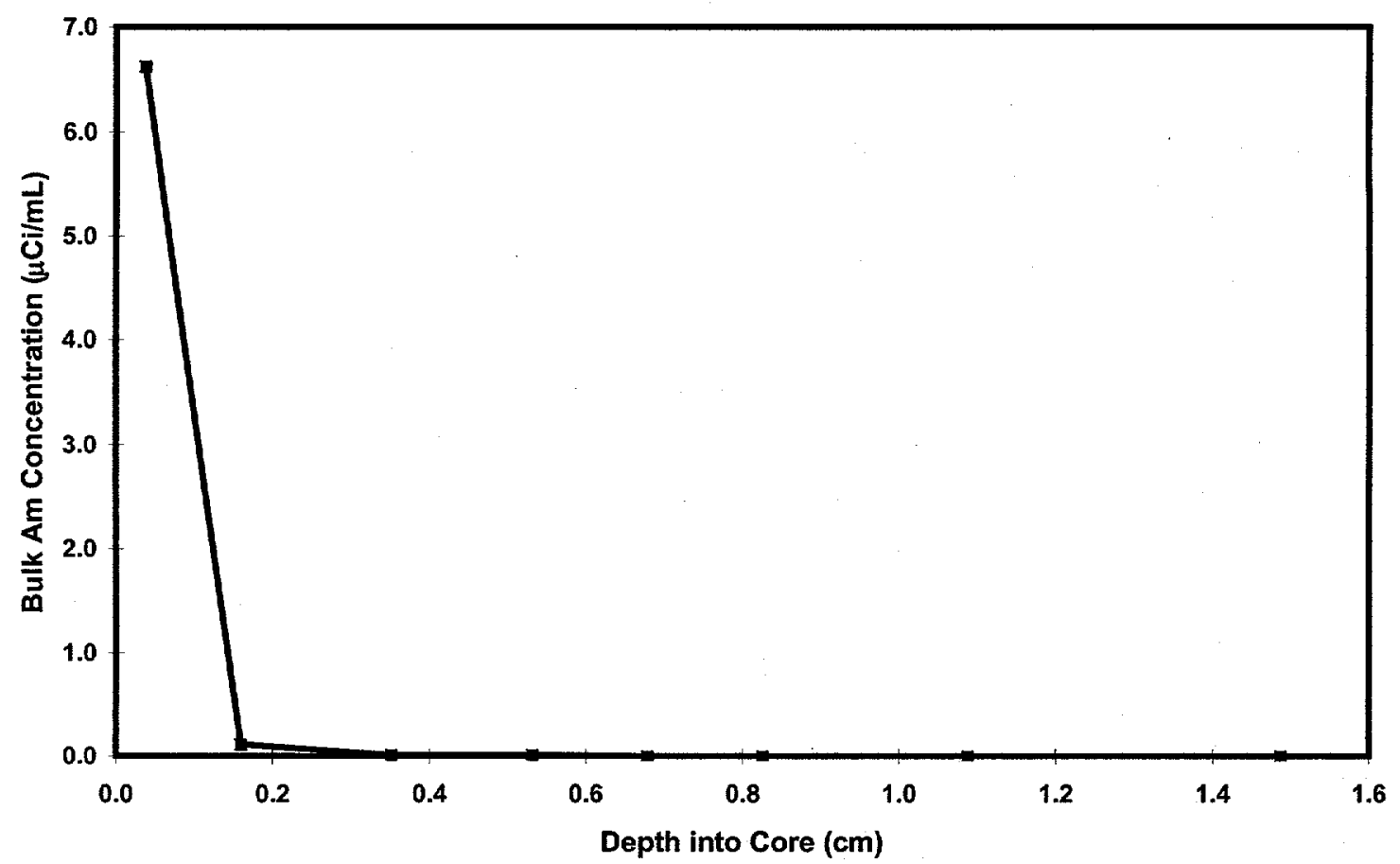

Figure 1. Measured ${ }^{241} \mathrm{Am}$ activity per unit rock volume as a function of depth into core. 




Figure 2. Measured ${ }^{241} \mathrm{Pu}$ activity per unit rock volume as a function of depth into core. 


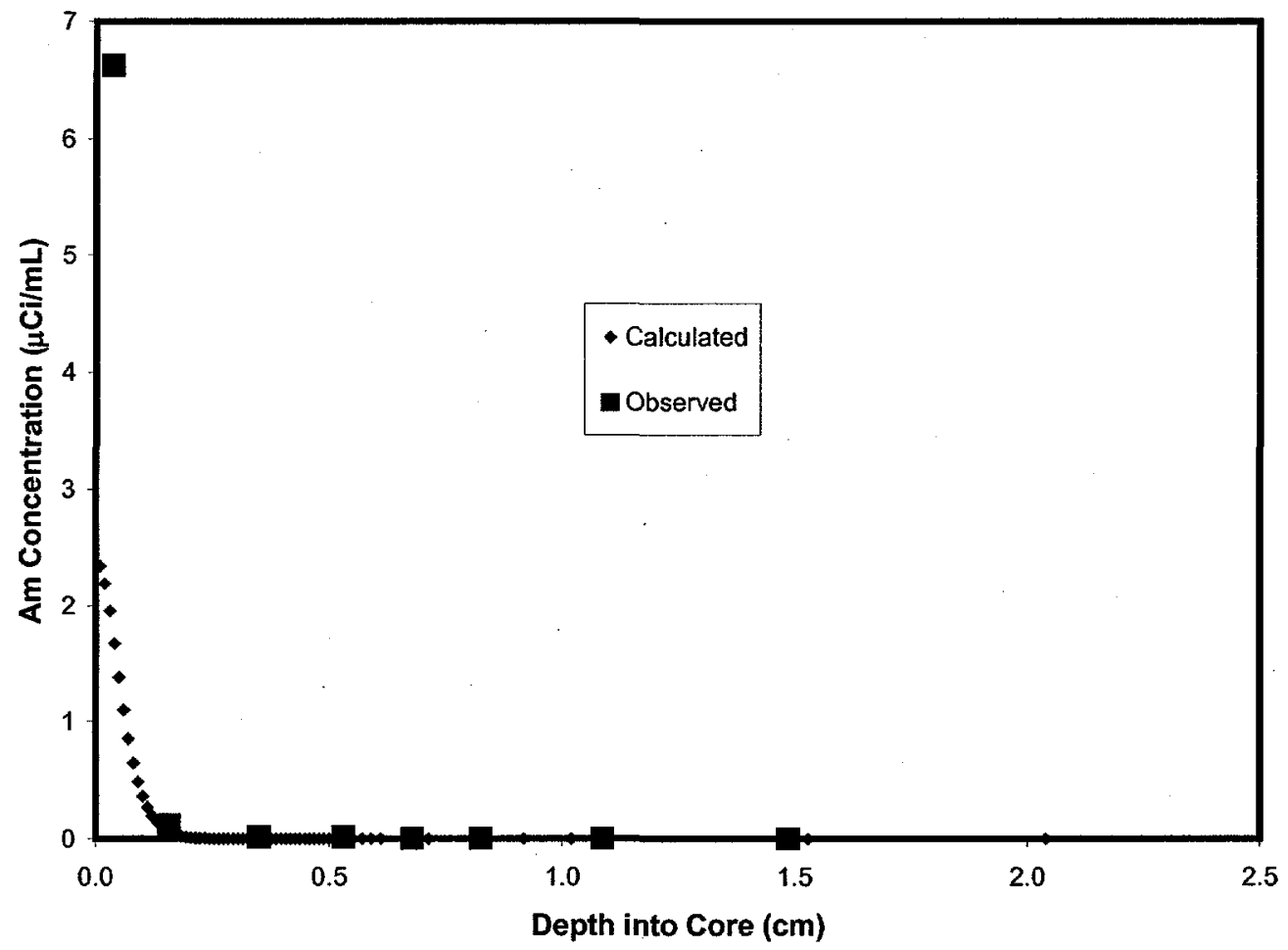

Figure 3. Comparison of measured ${ }^{241} \mathrm{Am}$ activity per unit rock volume to results of calculation for retardation factor $R=10^{6}$. 


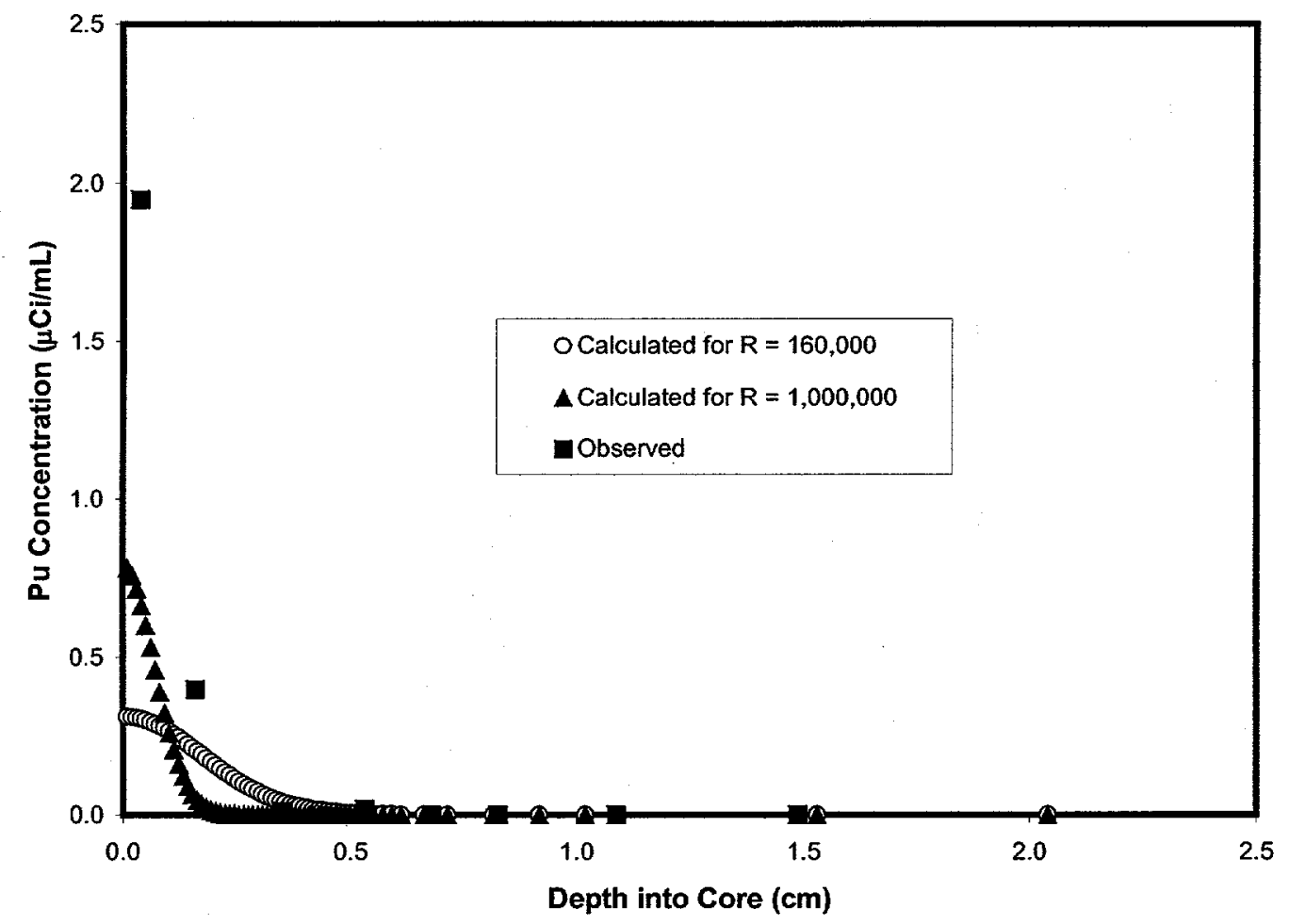

Figure 4. Comparison of measured ${ }^{241} \mathrm{Pu}$ activity per unit rock volume to results of calculation for retardation factors $R=160,000$ and $R=1,000,000$. 